\title{
Capacity Preserve Assignment Scheduling Algorithm in context of Determination System for Cloud Computing
}

\author{
G. Kavitha, I. Mary Linda, N. Priya
}

\begin{abstract}
Booking figuring is reliably a fervently issue in appropriated processing condition. Remembering the true objective to take out system bottleneck and modify stack logically. A stack changing endeavor booking count in light of weighted self-assertive and input frameworks was proposed in this paperFrom the outset the picked cloud masterminding host picked assets by necessities and made static estimation, and some time later coordinated them; other than the tally picked assets from which composed by weight self-confidently; by then it got standing out powerful data from effect burden to channel and sort the left. Finally it accomplished oneself adaptively to structure stack through information systems. The examination demonstrates that the calculation has stayed away from the framework bottleneck adequately and has accomplished adjusted burden and furthermore self-flexibility to it.keywords: Task Scheduling; Feedback Mechanism; Cloud Computing; Load Balancing.
\end{abstract}

\section{INTRODUCTION}

Distributed computing is the further improvement of the exploration on the conventional parallel figuring, circulated preparing, lattice registering and matrix stockpiling in view of a group, or the particular illustrative of the commercialization of software engineering idea $[1,2]$. Distributed computing condition association is for the most part partitioned into brought together and shared, the unified registering condition is anything but difficult to be actualized and subsequent to knowing the running condition of the worldwide assets, the booking hub executes the errand planning and dispenses undertakings sensibly, yet when the framework is bigger, incorporated assignment planning process influences the execution and solidness of the booking hub to end up noticeably the framework bottleneck. Subsequently, the brought together booking is reasonable for little scale distributed computing condition [3,4]. Shared distributed computing condition takes care of the bottleneck issues existing in unified booking mode, supporting dynamic section and exit of registering hub and reasonable for expansive scale processing condition. Be that as it may, shared planning calculation is hard to be outlined and executed. In an obscure condition of worldwide assets, to

Revised Manuscript Received on July 22, 2019.

G. Kavitha , Department of CSE, Bharath Institute of Higher Education and Research, Chennai, Tamilnadu, India.

I. Mary Linda, Department of CSE, Bharath Institute of Higher Education and Research, Chennai, Tamilnadu, India.

N. Priya, Department of CSE, Bharath Institute of Higher Education and Research, Chennai, Tamilnadu, India. plan assets just in light of nearby data isn't probably going to accomplish the objective of booking streamlining. In spite of the fact that the booking procedure of shared planning calculations, for example, subterranean insect settlement and molecule swarm has a tendency to be worldwide ideal, the calculation is hard to be executed, the booking procedure is intricate and the cost of registering and system transmission is expansive $[5,6]$.

As indicated by the consequences of inquires about in writing $[7,8]$, at introduce the greater part of the distributed computing condition more often than not utilizes moderately basic booking calculations and at the season of undertaking planning and asset allotment cloud stage may seem uneven load [9]. These planning calculations dispatches undertakings of insignificant and most punctual fulfillment time to the relating assets, or dispatches errands of maximal and soonest culmination time to the comparing assets, or pick dispatching hubs of negligible estimation of trust and advantage. They don't deal with the connection between the hub load and undertaking portion. On the off chance that some of unequal or over-burden hubs are chosen, it will lessen the general execution of the framework $[10,11]$.

Thusly, as indicated by the inadequate framework execution in distributed computing condition conceivably caused by uneven load, a disseminated booking calculation in light of weighted irregular $[12,13]$ and input component was proposed in this paper. On the introduce of expanding calculation usage many-sided quality indistinctively, it ensures that astounding hubs won't be over-burden and there is a possibility for general execution registering hubs to execute errands by utilizing the weighted arbitrary, over-burden appraisal and criticism methodology [14, 15].

\section{Process}

The depiction of errand planning process is as per the following:

(1) Select the planning host. Clients pick a host in the registering condition to surrender errands as per a specific procedure, in Figure. 1 the client chooses $\mathrm{Ni}$ to submit errands, $\mathrm{Ni}$ is in charge of assessing the running condition of registering assets in the framework, dispatching assignments to the submission have, observing the variety of the errand status and nourishing the data of undertaking submission [16, 17].

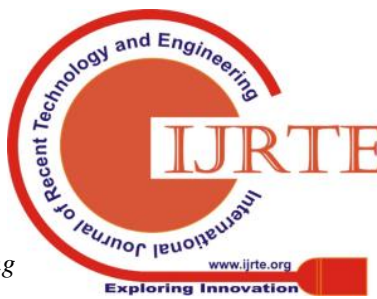


(2) Filter static asset data. The planning host utilizes design necessities of assignment assets, wipes out assets that doesn't face the base arrangement of undertaking submission, utilizes vector institutionalization technique to assess various static pointers of assets extensively in light of static asset data in the nearby capacity, sort s assets in light of the benefits of markers and utilizations probabilistic calculation to choose a few reinforcement registering assets $[18,19]$.

(3) Access dynamic data asset. Access the constant data of reinforcement registering assets through the system.

(4) Overload judgment. Dispose of the assets of a marker above over-burden standard as per the ongoing data. Assess remaining figuring assets exhaustively utilizing vector institutionalization technique and click the registering asset of the most elevated marker to undergo undertakings. In the event that all of reinforcement assets are disposed of due to over-burden judgment, backpedal to step (2), flitter the static asset data once more. Be that as it may, the separating procedure dispenses with the past reinforcement figuring assets and modifies the likelihood calculation, letting all the more processing assets chose. After the booking, alter the likelihood calculation as per the proportion of the quantity of reinforcement hosts to the quantity of outstanding hosts after over-burden result [20, 21]

(5) Scheduling host conveys undertakings to the execution unit, screens the execution status of the assignment and encourages back the execution comes about.

(6) Geometric weighted coefficient input control. Modify the geometric weighted coefficient as per the proportion of the quantity of reinforcement hosts to the quantity of outstanding hosts after over-burden judgment [22, 23].

Asset Requirements Description

The calculation depicted in this paper depends on the assignment procedure which has been investigated and the errand which has been deteriorated. The sub-errands of each undertaking have atomicity, that is no priority imperatives, not running crosswise over hubs and nuclear. Each subtask can introduce least arrangement prerequisite to assets which execute undertakings [24, 25].

Diverse handling rationale of undertaking business impacts that errands have exceptional prerequisites for a few properties of processing assets, for instance, register concentrated assignments are probably going to have higher interest for CPU execution and memory limit, and capacity escalated errands are probably going to have higher interest for hard plate or system transfer speed, along these lines $[26,27]$.

\section{ASSET REQUIREMENTS DESCRIPTION}

The calculation depicted in this paper depends on the assignment procedure which has been investigated and the errand which has been deteriorated. The sub-errands of each undertaking have atomicity that is no priority imperatives, not running crosswise over hubs and nuclear. Each subtask can introduce least arrangement prerequisite to assets which execute undertakings [28].

Diverse handling rationale of undertaking business impacts that errands have exceptional prerequisites for a few properties of processing assets, for instance, register concentrated assignments are probably going to have higher interest for CPU execution and memory limit, and capacity escalated errands are probably going to have higher interest for hard plate or system transfer speed, along these lines [29].

\section{RESULTS AND DISCUSSION}

The paper portrays the figuring unit which can actualize the capacity of executing errands as the asset. As indicated by various capacities, assets can be isolated into processing assets, stockpiling assets and system assets, and so on. incorporates processor limit, memory, stockpiling limit, hard plate stockpiling limit, organize correspondence limit, unwavering quality and line stack [30].

Each property of assets can be measured through particular esteem. The planning calculation utilizes property estimation as the premise of assessing asset execution. RS procincorporates three principle properties, the quantity of processors, overwhelming recurrence and operation stack parameter esteems,

In (6), the memory stack, circle load and system stack

The dependability is measured through $r(t)$, the effectively finished likelihood of a few assignments that assets execute as of late [31].

The line stack is found out through $\mathrm{q}(\mathrm{t})$, the proportion of the quantity of errands acknowledged by assignment handling line at present to the quantity of the undertakings that assignment preparing line can hold. $\mathrm{q}(\mathrm{t})$ is characterized as takes after: Asset Attribute Value Standardization. Among the choice issues of multi-target characteristic, the method for quantizing properties straightforwardly influences target evaluation. The paper utilizes various pointers during the time spent assessing assets; every marker has diverse unit and measurement. Keeping in mind the end goal to mirror the real execution condition of the assets better, every pointer should be analyzed under brought together measurements; along these lines, previously assessing each figuring hub asset extensively, we require measurement and institutionalize related markers. The paper utilizes the geometric mean technique in the vector institutionalization strategy [32-35] to institutionalize the asset characteristics, the technique is easy to compute and affected by the outrageous esteem littler.

\section{Calculation ImPlementation}

\section{A. Assets Filtering On-Demand and Static Attribute Quantization}

Separating Resources On-Demand. After the booking unit gets the undertaking demand, as indicated by the equation (1)- (9), the calculation channels the assets in light of the static characteristics and chooses $u$ accessible asset hubs face the base necessities for the assignment, articulation. Accessible Resources Static Attribute Quantization. Static asset trait unaltered piece of asset quality pointers amid the running of the framework. As per the definition (5) and (6), static quality marker of a solitary registering hub [36-41].

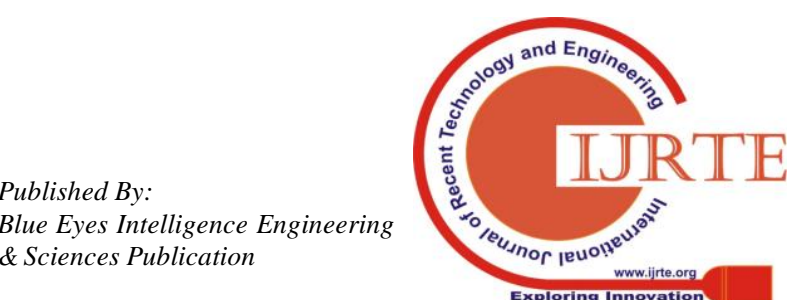




\section{CONCLUSION}

This paper proposed a weighted irregular booking calculation in light of the shared distributed computing condition, the asset properties are isolated in sections, the static and dynamic, assessed individually. calculation utilizes the arbitrary system, over-burden evaluation and input et cetera to guarantee that the hubs with incredible execution won't be overburdened in light of submitting undertakings initially to the assets with the best execution. In the meantime the assets with general execution can possibly play out an errand. The calculation can successfully adjust the heap, guarantees the fundamental load adjust of the hubs in the system and advances an answer for stack adjusting technique in distributed computing condition.

\section{REFERENCES}

[1] Kavitha, S. Prabakaran "A Novel Hybrid Segmentation Method with Particle Swarm Optimization and Fuzzy C-Mean Based On Partitioning the Image for Detecting Lung Cancer" International Journal of Engineering and Advanced Technology (IJEAT) ISSN: 2249-8958, Volume-8 Issue-5, June 2019

[2] Kumaravel A., Meetei O.N.,An application of non-uniform cellular automata for efficient cryptography,2013 IEEE Conference on Information and Communication Technologies, ICT 2013,V-,I-,PP-1200-1205,Y-2013

[3] Kumarave A., Rangarajan K.,Routing alogrithm over semi-regular tessellations, 2013 IEEE Conference on Information and Communication Technologies, ICT 2013,V-,I-,PP-1180-1184,Y-2013

[4] P. Kavitha, S. Prabakaran "Designing a Feature Vector for Statistical Texture Analysis of Brain Tumor" International Journal of Engineering and Advanced Technology (IJEAT) ISSN: 2249-8958, Volume-8 Issue-5, June 2019

[5] Dutta P., Kumaravel A.,A novel approach to trust based identification of leaders in social networks,Indian Journal of Science and Technology,V-9,I-10,PP--,Y-2016

[6] Kumaravel A., Dutta P.,Application of Pca for context selection for collaborative filtering,Middle - East Journal of Scientific Research,V-20,I-1,PP-88-93,Y-2014

[7] Kumaravel A., Rangarajan K.,Constructing an automaton for exploring dynamic labyrinths,2012 International Conference on Radar, Communication and Computing, ICRCC 2012,V-,I-,PP-161-165,Y-2012

[8] P. Kavitha, S. Prabakaran “Adaptive Bilateral Filter for Multi-Resolution in Brain Tumor Recognition" International Journal of Innovative Technology and Exploring Engineering (IJITEE) ISSN: 2278-3075, Volume-8 Issue-8 June, 2019

[9] Kumaravel A.,Comparison of two multi-classification approaches for detecting network attacks, World Applied Sciences Journal,V-27,I-11,PP-1461-1465,Y-2013

[10] Tariq J., Kumaravel A.,Construction of cellular automata over hexagonal and triangular tessellations for path planning of multi-robots,2016 IEEE International Conference on Computational Intelligence and Computing Research, ICCIC 2016,V-,I-,PP--,Y-2017

[11] Sudha M., Kumaravel A.,Analysis and measurement of wave guides using poisson method,Indonesian Journal of Electrical Engineering and Computer Science, V-8,I-2,PP-546-548,Y-2017

[12] Ayyappan G., Nalini C., Kumaravel A.,Various approaches of knowledge transfer in academic social network,International Journal of Engineering and Technology,V-,I-,PP-2791-2794,Y-2017

[13] Kaliyamurthie, K.P., Sivaraman, K., Ramesh, S. Imposing patient data privacy in wireless medical sensor networks through homomorphic cryptosystems 2016, Journal of Chemical and Pharmaceutical Sciences92.

[14] Kaliyamurthie, K.P., Balasubramanian, P.C. An approach to multi secure to historical malformed documents using integer ripple transfiguration 2016 Journal of Chemical and Pharmaceutical Sciences92.

[15] A.Sangeetha,C.Nalini,"'Semantic Ranking based on keywords extractions in the web", International Journal of Engineering \& Technology, 7 (2.6) (2018) 290-292

[16] S.V.GayathiriDevi,C.Nalini,N.Kumar,"An efficient software verification using multi-layered software verification tool "International Journal of Engineering \& Technology, 7(2.21)2018 454-457
[17] C.Nalini,ShwtambariKharabe,"A Comparative Study On Differen Techniques Used For Finger - Vein Authentication", International Journal Of Pure And Applied Mathematics, Volume 116 No. 82017 327-333, Issn: 1314-3395

[18] M.S. Vivekanandan and Dr. C. Rajabhushanam, "Enabling Privacy Protection and Content Assurance in Geo-Social Networks", International Journal of Innovative Research in Management, Engineering and Technology, Vol 3, Issue 4, pp. 49-55, April 2018.

[19] Dr. C. Rajabhushanam, V. Karthik, and G. Vivek, "Elasticity in Cloud Computing", International Journal of Innovative Research in Management, Engineering and Technology, Vol 3, Issue 4, pp. 104-111, April 2018.

[20] K. Rangaswamy and Dr. C. Rajabhushanamc, "CCN-Based Congestion Control Mechanism In Dynamic Networks", International Journal of Innovative Research in Management, Engineering and Technology, Vol 3, Issue 4, pp. 117-119, April 2018.

[21] Kavitha, R., Nedunchelian, R., "Domain-specific Search engine optimization using healthcare ontology and a neural network backpropagation approach", 2017, Research Journal of Biotechnology, Special Issue 2:157-166

[22] Kavitha, G., Kavitha, R., "An analysis to improve throughput of high-power hubs in mobile ad hoc network", 2016, Journal of Chemical and Pharmaceutical Sciences, Vol-9, Issue-2: 361-363

[23] Kavitha, G., Kavitha, R., "Dipping interference to supplement throughput in MANET", 2016, Journal of Chemical and Pharmaceutical Sciences, Vol-9, Issue-2: 357-360

[24] Michael, G., Chandrasekar, A.,"Leader election based malicious detection and response system in MANET using mechanism design approach", Journal of Chemical and Pharmaceutical Sciences(JCPS) Volume 9 Issue 2, April - June 2016

[25] Michael, G., Chandrasekar, A.,"Modeling of detection of camouflaging worm using epidemic dynamic model and power spectral density", Journal of Chemical and Pharmaceutical Sciences(JCPS) Volume 9 Issue 2, April - June 2016 .

[26] Pothumani, S., Sriram, M., Sridhar, J., Arul Selvan, G., Secure mobile agents communication on intranet,Journal of Chemical and Pharmaceutical Sciences, volume 9, Issue 3, Pg No S32-S35, 2016

[27] Pothumani, S., Sriram, M., Sridhar , Various schemes for database encryption-a survey, Journal of Chemical and Pharmaceutical Sciences, volume 9, Issue 3, Pg NoS103-S106, 2016

[28] Pothumani, S., Sriram, M., Sridhar, A novel economic framework for cloud and grid computing, Journal of Chemical and Pharmaceutical Sciences, volume 9, Issue 3, Pg No S29-S31, 2016

[29] Priya, N., Sridhar, J., Sriram, M. "Ecommerce Transaction Security Challenges and Prevention Methods- New Approach” 2016 ,Journal of Chemical and Pharmaceutical Sciences, JCPS Volume 9 Issue 3.page no:S66-S68

[30] Priya, N.,Sridhar,J.,Sriram, M."Vehicular cloud computing security issues and solutions" Journal of Chemical and Pharmaceutical Sciences(JCPS) Volume 9 Issue 2, April - June 2016

[31] Priya, N., Sridhar, J., Sriram, M. "Mobile large data storage security in cloud computing environment-a new approach" JCPS Volume 9 Issue 2. April - June 2016

[32] Anuradha.C, Khanna.V, "Improving network performance and security in WSN using decentralized hypothesis testing "Journal of Chemical and Pharmaceutical Sciences(JCPS) Volume 9 Issue 2, April - June 2016.

[33] Anuradha.C, Khanna.V, "A novel gsm based control for e-devices" Journal of Chemical and Pharmaceutical Sciences(JCPS) Volume 9 Issue 2, April - June 2016

[34] Anuradha.C, Khanna.V, "Secured privacy preserving sharing and data integration in mobile web environments " Journal of Chemical and Pharmaceutical Sciences(JCPS) Volume 9 Issue 2, April - June 2016.

[35] Sundarraj, B., Kaliyamurthie, K.P. Social network analysis for decisive the ultimate classification from the ensemble to boost accuracy rates 2016 International Journal of Pharmacy and Technology

[36] Sundarraj, B., Kaliyamurthie, K.P. A content-based spam filtering approach victimisation artificial neural networks 2016 International Journal of Pharmacy and Technology83.

[37] Sundarraj, B., Kaliyamurthie, K.P. Remote sensing imaging for satellite image segmentation 2016 International Journal of Pharmacy and Technology8 3.

[38] Sivaraman, K., Senthil, M. Intuitive driver proxy control using artificial intelligence 2016 International Journal of Pharmacy and Technology84.

[39] Sivaraman, K., Kaliyamurthie, K.P. Cloud computing in mobile technology 2016 Journal of Chemical and Pharmaceutical Sciences92.

[40] Sivaraman, K., Khanna, V. Implementation of an extension for browser to detect vulnerable elements on web pages and avoid click jacking 2016 Journal of Chemical and Pharmaceutical Sciences92. 


\section{AUTHORS PROFILE}

G. Kavitha, Associate Professor, Department of Computer Science \& Engineering, Bharath Institute of Higher Education and Research, Chennai, India

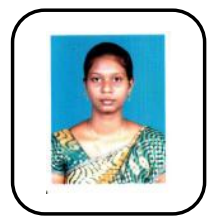

I. Mary Linda, Assistant Professor, Department of Computer Science \& Engineering, Bharath Institute of Higher Education and Research, Chennai, India

N.Priya, Assistant Professor, Department of Computer Science \& Engineering, Bharath Institute of Higher Education and Research, Chennai, India 